\title{
Rehabilitation in Patients With Coronary Heart Disease
}

\author{
Participation and Its Effect on Prognosis
}

\author{
Axel Schlitt, Patricia Wischmann, Andreas Wienke, Florian Hoepfner, Frank Noack, \\ Rolf-Edgar Silber, Karl Werdan
}

\section{SUMMARY}

Background: In Germany, rehabilitation is considered to be indicated after an acute hospital stay for the treatment of a severe cardiac condition. In comparative studies, at least $51 \%$ of German hospital patients with coronary heart disease (CHD) who were entitled to rehabilitative measures actually took part in rehabilitation.

Methods: We examined data on 1910 patients with CHD who took part in two prospective cohort studies at the University Hospital of Halle (Saale) in the years 2007-2011. We contacted these patients again with a questionnaire to determine which ones had undergone rehabilitation. For patients who died before we could contact them, the attempt was made to obtain the dates and causes of death from the local authorities. The primary endpoint of was overall mortality.

Results: The median duration of follow-up was $136 \pm 71$ weeks. 727 patients $(38.1 \%)$ had applied for rehabilitation during their acute hospitalization, but only 552 patients $(28.9 \%)$ actually underwent it. Patients who did not undergo rehabilitation were older than those who did ( $68.6 \pm 10.3$ vs. $64.9 \pm 10.5$ years) and suffered more commonly from diabetes $(41.3 \%$ vs. $33.7 \%$; $p=0.002)$, arterial hypertension ( $89.2 \%$ vs. $85.3 \% ; p=0.017)$, and peripheral arterial occlusive disease ( $15.3 \%$ vs. $9.8 \% ; p=0.002)$. There were more smokers in the rehabilitation group. Kaplan-Meier analysis and multivariate Cox regression analysis both showed that the patients who underwent rehabilitation had lower mortality (hazard ratio $0.067,95 \%$ confidence interval $0.025-0.180, p<0.001$ ).

Conclusion: Rehabilitation for cardiac patients was associated with lower mortality. Fewer patients underwent rehabilitation in this study than in other, comparable studies. Those who did not were older and had a greater burden of accompanying disease.

\section{Cite this as:}

Schlitt A, Wischmann P, Wienke A, Hoepfner F, Noack F, Silber RE, Werdan K: Rehabilitation in patients with coronary heart disease-participation and its effect on prognosis. Dtsch Arztebl Int 2015; 112: 527-34.

DOI: 10.3238/arztebl.2015.0527
Paracelsus Harz Clinic Bad Suderode, Quedlinburg: Prof. Dr. med. Schlitt, MHA

Department of Internal Medicine III, University Hospital of Halle (Saale): Prof. Dr. med. Schlitt, MHA, Wischmann, Hoepfner, Prof. Dr. med. Werdan

Institute for Medical Epidemiology, Biometrics and Computer Science, Martin-Luther-University HalleWittenberg, Halle (Saale): Prof. Dr. rer. nat. habil. Wienke

Department of Internal Medicine I, University Hospital of Halle (Saale): Noack

Department of Cardiac und Thoracic Surgery, University Hospital of Halle (Saale): Prof. Dr. med. Silber
$\mathbf{A}$ lthough cardiovascular disease remains the leading cause of death in Germany, it has declined in recent decades. For example, the mortality rate for acute myocardial infarction in Germany fell from 118.4 to 63.7 per 100000 population between 1980 and 2011 (1). In absolute terms, this figure fell from 92801 (1980) to 52113 (2011) (1). The main reason for the fall in cardiovascular deaths is improved prevention, diagnosis, and treatment of coronary heart disease (CHD) (1). However, this improvement should be treated as potentially transient, as risk factors for atherosclerotic diseases, such as diabetes mellitus and obesity, are continually increasing. The obesity rate in Germany is now $45.5 \%$ among men and $29.5 \%$ among women; the number of people living with diabetes mellitus, currently around 6 million, will rise by approximately 1.5 million by $2030(2,3)$.

In addition, analysis of inpatient mortality figures in different federal states for ischemic heart disease, particularly acute myocardial infarction, shows substantial differences between states. İ otably, myocardial infarction mortality figures are higher in the former East Germany, with the highest level in Saxony-Anhalt at 104 per 100000 population per year, than in the western German federal states, with the lowest level in Bremen at 35 per 100000 population per year (1). The causes of differences between states are unclear. Possible factors discussed include differing health care, lower densities of physicians in relation to populations, a less effective emergency physician system, longer time to hospital admission, and different education levels among the population with less health awareness (1). A recent article has shown that Saxony-Anhalt is the federal state with the highest levels of traditional risk factors-diabetes mellitus, arterial hypertension, obesity, and smoking — among the general population (4).

Outpatient and inpatient rehabilitation are an essential part of tertiary prevention for the long-term success of medical treatment for acute and chronic heart disease $(5,6)$. Recent reviews of the 148 randomized trials conducted to date, which involved more than 98000 patients, have shown that such rehabilitation reduces both cardiovascular and total mortality for patients with CHD and the rate of hospital readmission for patients with heart failure $(7,8)$ (Figure 1). 


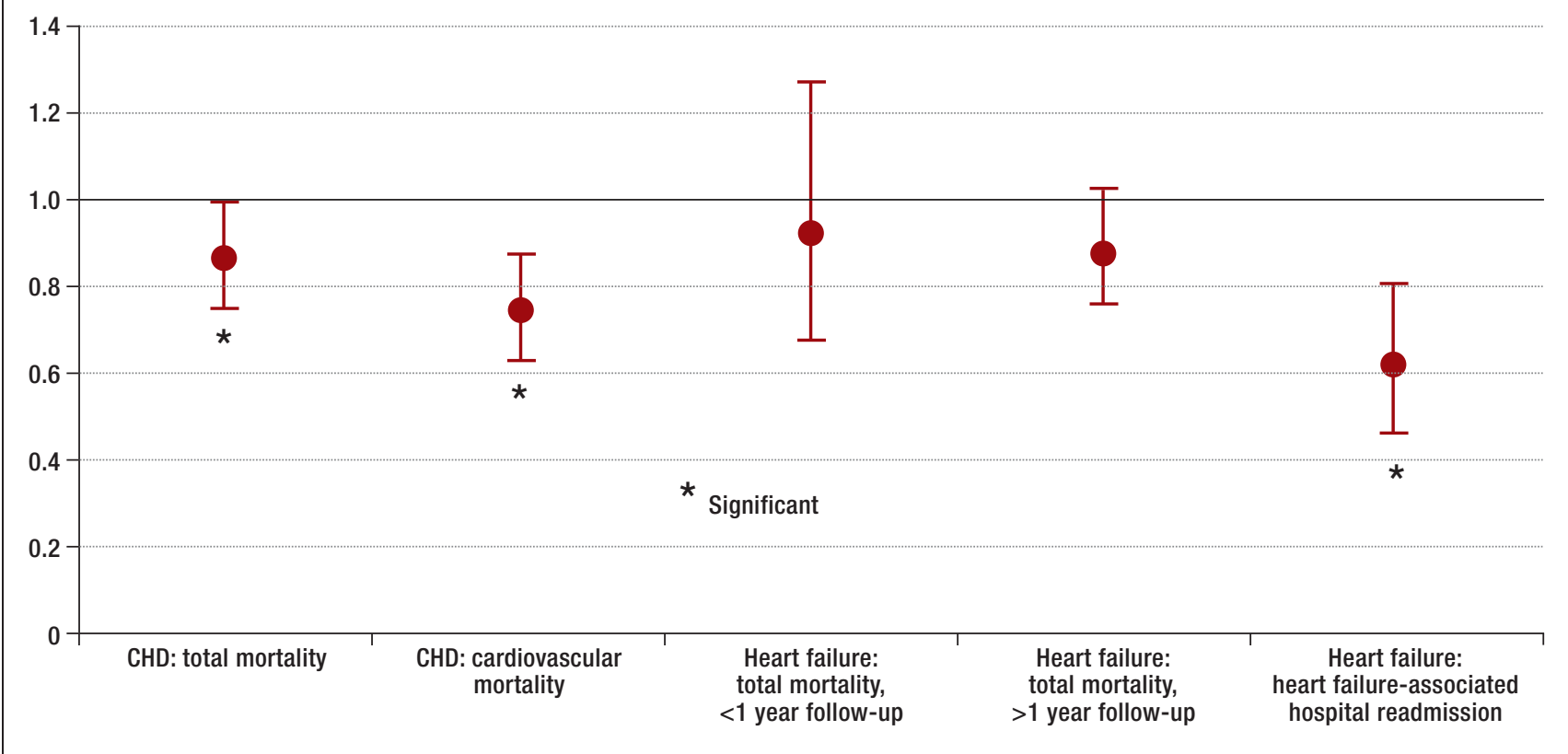

Effects of a training-based rehabilitation program on total mortality and cardiovascular mortality in patients with coronary heart disease (CHD), and on medium-term ( $<1$ year) and long-term ( $>1$ year) mortality and onset of renewed heart failure symptoms (with and without hospital stay) in patients with heart failure. Odds ratios are based on systematic reviews of the Cochrane Library intervention analyses (point estimates, including upper and lower confidence intervals) (according to [7]).

This retrospective study investigated access to rehabilitation following an acute inpatient hospital stay among patients with CHD in Saxony-Anhalt as a potential factor in high cardiovascular mortality.

\section{Methods}

The first step in this retrospective cohort study was the analysis of the electronic datasets and records of 1910 patients who had received inpatient treatment at the Department of Internal Medicine III and the Department of Cardiac und Thoracic Surgery, at the University Hospital in Halle (Saale) between 2007 and 2011. Patients were recruited prospectively either in the study on the role of CD16-positive monocytes in CHD (PHAMOS, ClinicalTrials.gov identifier I CT01442948) (9) between 2007 and 2009 or in the study on the role of evidence of periodontitis in patients with CHD (Periodontitis and Coronary Heart Disease, ClinicalTrials.gov identifier I CT01045070) (10) between 2009 and 2011. The essential inclusion criteria for both studies were an inpatient stay at the University Hospital in Halle (Saale) and angiographically confirmed CHD. Patients of all ages were included, provided they were at least 18 years old. Patients with no written declaration of consent and those with a life expectancy of less than 12 months were excluded from both studies.

The inclusion criterion for this analysis was recruitment in one of the two studies mentioned above, with the aim of obtaining additional knowledge about participation or nonparticipation in cardiac rehabili- tation within six months following the index stay, on either an inpatient or an outpatient basis. The primary endpoint was defined as total mortality. For data collection, patients were sent a new questionnaire unless the original studies had established that they had died (9, 10). The questionnaire was completed by 1236 patients. As in the original studies, patients were contacted by telephone if no reply was received. If patients had died in the meantime, attempts were made to ascertain the cause and date of death via the health office of the relevant area. For patients who did not reply and who were impossible to contact by telephone, the relevant information was requested in writing from the appropriate municipal authority.

Most information on potential requests for rehabilitation and on participation was taken from discharge letters and social services documents. A questionnaire was also sent to patients in 2012. The investigation had obtained the approval of the Ethics Committee of Medical Faculty of the Martin Luther University HalleWittenberg for renewed contact with the patients.

\section{Statistical analysis methods}

Continuous, normally distributed variables were described using means and standard deviations, while continuous variables with skewed distribution were described using medians and interquartile ranges. Discrete variables were recorded in terms of percentages. The $t$-test was used to compare the means of metric, independent, normally distributed variables. The 
Mann-Whitney U-test was used to compare variables with skewed distribution. The chi-square test was used for nominal variables. Survival probabilities for subgroups were calculated using the Kaplan-Meier method (Figure 2). Survival curves were compared using the log-rank test. The effect of rehabilitation was analyzed using the Cox regression model, both univariately and multivariately (adjusted for potential influencing factors). All $p$-values shown are estimated as exploratory values.

\section{Results}

The mean follow-up time was $136 \pm 71$ weeks (range: 1 to 303 weeks). In 112 patients $(5.8 \%)$ there was no information available on participation or nonparticipation in rehabilitation or on mortality. As a result, there remained 552 patients in the group of rehabilitation participants and 1246 in the group of nonparticipants. Of these 1798 patients, 315 (17.5\%) died during the investigation period.

\section{Rehabilitation}

During the index stay, 727 requests for cardiac rehabilitation were made. In terms of permission for rehabilitation, for $20 \%$ of requests $(n=145)$ it could not be determined why a request was not approved or why the request procedure was not completed. While 552 patients took up the offer of cardiac rehabilitation, 30 patients declined it although it had been offered.

\section{Risk factors}

The mean age of patients when admitted as inpatients was $67.5 \pm 10.5$ years (range: 27 to 97 years). Those who did not participate in rehabilitation were older on average than those who did, at $68.6 \pm 10.3$ years (range: 27 to 97 years) versus $64.9 \pm 10.5$ years (range: 34 to 88 years $)(p<0.001)$. There were further differences for the following variables:

- Diabetes mellitus ( $41.3 \%$ of nonparticipants versus $33.7 \%$ of participants; $p=0.002$ )

- Arterial hypertension (89.2\% of nonparticipants versus $85.3 \%$ of participants; $p=0.017$ )

- Peripheral arterial occlusive disease $(15.3 \%$ of nonparticipants versus $9.8 \%$ of participants; $\mathrm{p}=0.002$ )

- Percutaneous coronary intervention before or during inpatient stay $(62.7 \%$ of nonparticipants versus $52.5 \%$ of participants; $\mathrm{p}<0.001$ )

In addition, left ventricular ejection fraction was lower among nonparticipants than among participants, at $41.1 \pm 21.8 \%$ (range: 11 to $79 \%$ ) versus $44.2 \pm$ $20.6 \%$ (range: 15 to $77 \%)(p=0.030)$.

In contrast, a history of recent or previous coronary artery bypass graft surgery (CABG) was more common among participants than among nonparticipants: $46.2 \%$ versus $30.7 \%(\mathrm{p}<0.001)$ (Table 1).

\section{Diagnosis on admission and coronary heart disease}

While angina pectoris was more common as reason for admission among those who did not undergo rehabili-

\section{FIGURE 2}

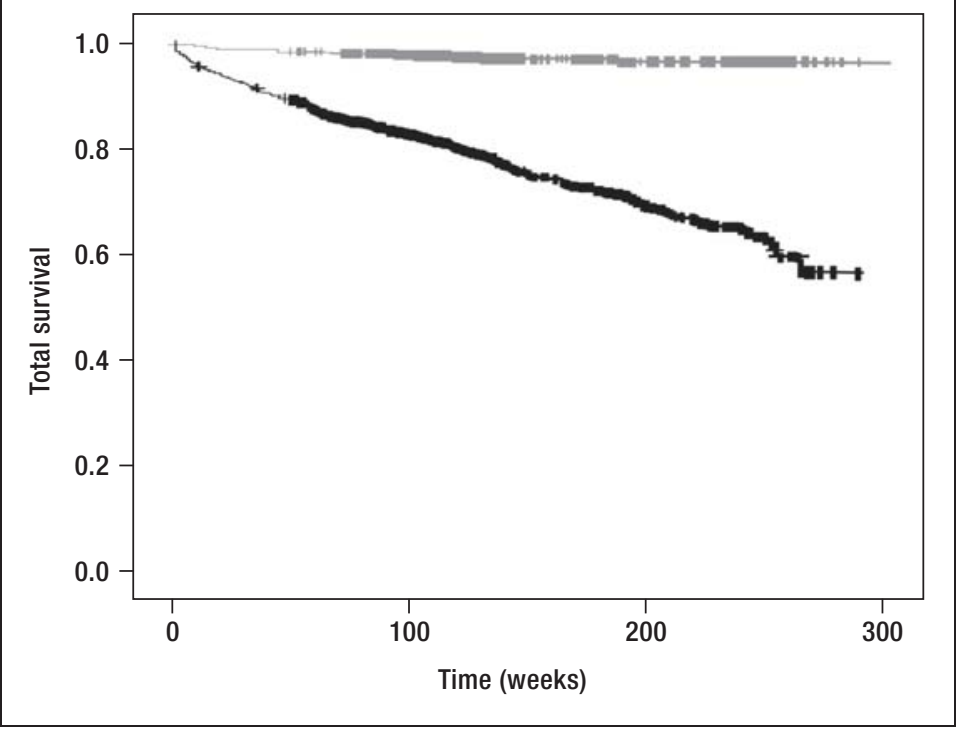

Kaplan-Meier analysis of total mortality, comparing those who underwent rehabilitation (gray) versus those who did not (black)

tation $(31.9 \%$ versus $15.9 \%$; $\mathrm{p}<0.001)$, ST-elevation myocardial infarction (STEMI) was more common as grounds for admission among those who did (15.6\% versus $3.2 \%$; p <0.001), as was non-ST-elevation myocardial infarction (I STEMI) (16.5\% versus $8.7 \%$; $\mathrm{p}<0.001$ ) (Table 1).

Regarding the number of diseased vessels, singlevessel coronary artery disease was more common among those who did not undergo rehabilitation (24.8\% of nonparticipants versus $19.6 \%$ of participants). Triple-vessel coronary artery disease was more common among those who did undergo rehabilitation $(53.6 \%)$ than among those who did not (40.8\%) $(\mathrm{p}<0.001)$ (Table 1).

\section{Laboratory parameters}

Table 1 shows patients' laboratory parameters on admission to the hospital. There were differences for creatinine, HDL cholesterol, hemoglobin, C-reactive protein (CRP), and WBC.

\section{Discharge medication}

Angiotensin receptor blockers (ARBs) (19.2\% of participants versus $26.6 \%$ of nonparticipants) and diuretics $(62.0 \%$ of participants versus $67.4 \%$ of nonparticipants) were less commonly recorded among participants' discharge medication (Table 1). Regarding platelet aggregation inhibitors, a total of $43.3 \%$ of patients were prescribed combination therapy consisting of acetylsalicylic acid (ASS) and a P2 $\mathrm{Y}_{12}$ inhibitor. There are also differences between the two groups in terms of oral anticoagulants as discharge medication $(17.8 \%$ of participants versus $25.6 \%$ of nonparticipants; $\mathrm{p}<0.001)$. The percentage of 
Clinical characteristics, diagnosis on admission, medication, and number of diseased vessels in patients who did and did not undergo rehabilitation

\begin{tabular}{|c|c|c|c|c|}
\hline Variable & Total & $\begin{array}{c}\text { REHAB } \\
(n=552)\end{array}$ & $\begin{array}{c}\text { Non-REHAB } \\
(n=1246)\end{array}$ & p-value \\
\hline Age, M (SD) & $67.5 \pm 10.5$ & $64.9 \pm 10.5$ & $68.6 \pm 10.3$ & $<0.001$ \\
\hline Male sex, n (\%) & $1282(71.3)$ & $404(73.2)$ & $878(70.5)$ & 0.249 \\
\hline $\begin{array}{l}\text { Clinical history, } n(\%) \\
\text { Active smokers } \\
\text { Diabetes mellitus } \\
\text { Arterial hypertension } \\
\text { Dyslipoproteinemia } \\
\text { Family history of CHD } \\
\text { PAOD } \\
\text { PCI } \\
\text { CABG } \\
\text { Stroke/TIA } \\
\text { Atrial fibrillation }(n=930)\end{array}$ & $\begin{array}{l}253(14.2) \\
700(39.0) \\
1580(88.0) \\
1128(63.4) \\
740(41.6) \\
245(13.6) \\
1064(59.5) \\
636(35.5) \\
237(13.2) \\
388(41.7)\end{array}$ & $\begin{array}{l}89(16.2) \\
186(33.7) \\
471(85.3) \\
338(61.8) \\
237(43.0) \\
54(9.8) \\
289(52.5) \\
254(46.2) \\
67(12.2) \\
74(33.5)\end{array}$ & $\begin{array}{l}164(13.3) \\
514(41.3) \\
1109(89.2) \\
790(64.1) \\
503(40.9) \\
191(15.3) \\
775(62.7) \\
382(30.7) \\
170(13.7) \\
314(44.3)\end{array}$ & $\begin{array}{l}0.114 \\
0.002 \\
0.019 \\
0.357 \\
0.409 \\
0.002 \\
<0.001 \\
<0.001 \\
0.385 \\
0.014\end{array}$ \\
\hline $\begin{array}{l}\text { BMI, } \mathrm{kg} / \mathrm{m}^{2} \\
\text { LVEF, } \%\end{array}$ & $\begin{array}{c}28.4 \pm 4.7 \\
41.7 \pm 21.6\end{array}$ & $\begin{array}{c}28.5 \pm 4.4 \\
44.2 \pm 20.6\end{array}$ & $\begin{array}{c}28.4 \pm 4.8 \\
41.1 \pm 21.8\end{array}$ & $\begin{array}{l}0.836 \\
0.030\end{array}$ \\
\hline $\begin{array}{l}\text { Diagnosis on admission, } \mathrm{n}(\%) \\
\text { Stable angina pectoris } \\
\text { Acute coronary syndrome } \\
\text { Unstable angina pectoris } \\
\text { NSTEMI } \\
\text { STEMI } \\
\text { Pacemaker/ICD implantation } \\
\text { Decompensated heart failure } \\
\text { Hypertensive crisis } \\
\text { Cardiac arrhythmia } \\
\text { Pulmonary embolism } \\
\text { Other }\end{array}$ & $\begin{array}{l}665(37.0) \\
810(45.1) \\
485(27.0) \\
199(11.1) \\
126(7.0) \\
33(1.8) \\
135(7.5) \\
24(1.3) \\
81(4.5) \\
3(0.2) \\
44(2.4)\end{array}$ & $\begin{array}{l}227(41.1) \\
265(48.0) \\
88(15.9) \\
91(16.5 \\
86(15.6) \\
2(0.4) \\
33(6.0) \\
1(0.2) \\
11(2.0) \\
2(0.4) \\
10(1.8)\end{array}$ & $\begin{array}{c}438(35.2) \\
545(43.8) \\
397(31.9) \\
108(8.7) \\
40(3.2) \\
31(2.5) \\
102(8.2) \\
23(1.8) \\
70(5.6) \\
1(0.1) \\
34(2.7)\end{array}$ & $\begin{array}{l}0.016 \\
0.096 \\
<0.001 \\
<0.001 \\
<0.001 \\
0.002 \\
0.100 \\
0.005 \\
0.001 \\
0.117 \\
0.245\end{array}$ \\
\hline $\begin{array}{l}\text { No. of affected coronary vessels, } n(\%) \\
1 \\
2 \\
3\end{array}$ & $\begin{array}{l}417(23.2) \\
401(22.3) \\
804(44.7)\end{array}$ & $\begin{array}{l}108(19.6) \\
117(21.2) \\
296(53.6)\end{array}$ & $\begin{array}{l}309(24.8) \\
284(22.8) \\
508(40.8)\end{array}$ & $\begin{array}{r}0.015 \\
0.448 \\
<0.001\end{array}$ \\
\hline $\begin{array}{l}\text { Creatinine, } \mu \mathrm{mol} / \mathrm{L} \\
\text { Urea, } \mu \mathrm{mol} / \mathrm{L} \\
\text { Triglycerides, } \mathrm{mmol} / \mathrm{L} \\
\text { Total cholesterol, mmol/L } \\
\text { LDL C, mmol/L } \\
\text { HDL C, mmol/L } \\
\text { WBC, Gpt/L } \\
\text { Hemoglobin, } \mathrm{mmol} / \mathrm{L} \\
\text { CRP, mg/L }\end{array}$ & $\begin{array}{c}92(75 / 114.5) \\
6(4 / 9) \\
1.3(1 / 1.9) \\
4.5(3.8 / 5.6) \\
2.84( \pm 1.1) \\
1.0(0.8 / 1.2) \\
7.4(6.3 / 9.2) \\
8.1( \pm 1.2) \\
6.4(5 / 28.8)\end{array}$ & $\begin{array}{c}92(77 / 123.2) \\
6.5(4 / 10) \\
1.5(1.2 / 2.1) \\
4.9(3.8 / 5.7) \\
2.84( \pm 1.08) \\
1.0(0.8 / 1.2) \\
7.6(6.5 / 9.2) \\
7.9( \pm 1.2) \\
13.4(5.0 / 41.7)\end{array}$ & $\begin{array}{c}91(74.5 / 113) \\
6(4 / 9) \\
1.3(0.9 / 1.8) \\
4.5(3.7 / 5.5) \\
2.75( \pm 1.03) \\
1.0(0.9 / 1.3) \\
7.4(6.2 / 9.1) \\
8.1( \pm 1.2) \\
5.7(5.0 / 21.5)\end{array}$ & $\begin{array}{l}<0.001 \\
0.981 \\
0.514 \\
0.728 \\
0.132 \\
<0.001 \\
<0.001 \\
<0.001 \\
<0.001\end{array}$ \\
\hline $\begin{array}{l}\text { Beta-blockers, } n(\%) \\
\text { ACE inhibitors, } n(\%) \\
\text { Angiotensin receptor blockers, } n(\%) \\
\text { Diuretics, } n(\%) \\
\text { Calcium-channel blockers, } n(\%) \\
\text { Lipid reducers, } n(\%) \\
\quad \text { Statin } \\
\text { Ezetrol } \\
\text { Statin + ezetrol } \\
\text { Other } \\
\text { Oral anticoagulants, } n(\%) \\
\text { Platelet aggregation inhibitors, } n(\%) \\
\quad \text { ASS } \\
\text { P2Y } \\
\text { ASS + P2Yhibitor } \\
\text { Digitalis }\end{array}$ & $\begin{array}{c}1686(94.1) \\
1308(73.0) \\
436(24.3) \\
1178(65.7) \\
486(27.1) \\
\\
1485(82.7) \\
43(2.4) \\
80(4.5) \\
4(0.2) \\
415(23.2)\end{array}$ & $\begin{array}{l}525(95.1) \\
414(75.1) \\
106(19.2) \\
342(62.0) \\
134(24.3) \\
\\
465(84.2) \\
12(2.2) \\
14(2.5) \\
2(0.4) \\
98(17.8)\end{array}$ & $\begin{array}{c}1161(93.6) \\
894(72.1) \\
330(26.6) \\
836(67.4) \\
352(28.4) \\
1020(82.1) \\
31(2.5) \\
66(5.3) \\
2(0.2) \\
317(25.6) \\
390(31.5) \\
83(6.7) \\
523(42.2) \\
180(14.5)\end{array}$ & $\begin{array}{l}0.220 \\
0.181 \\
0.001 \\
0.024 \\
0.071 \\
0.097\end{array}$ \\
\hline
\end{tabular}

Continuous, normally distributed variables are represented by mean \pm standard deviation, continuous variables with skewed distribution by median (interquartile range), and discrete variables in absolute figures and percentages.

REHAB: Rehabilitation; M: Mean; SD: Standard deviation; CHD: Coronary heart disease; PAOD: Peripheral arterial occlusive disease; PCI: Percutaneous coronary intervention; CABG: coronary artery bypass graft surgery; TIA: Transient ischemic attack; BMI: Body mass index; LVEF: Left ventricular ejection fraction; NSTEMI: Non-ST-elevation myocardial infarction; STEMI: ST-elevation myocardial infarction; ICD: implantable cardioverter defibrillator; LDL C: Low-density lipoprotein cholesterol; HDL C: High-density lipoprotein cholesterol; WBC: white blood cells; CRP: C-reactive protein; ACE: Angiotensin converting enzyme; ASS: Acetylsalicylic acid 
Cox regression analyses*1

\begin{tabular}{|c|c|c|c|c|}
\hline & Hazard ratio & $\begin{array}{l}\text { Lower confidence } \\
\text { interval }\end{array}$ & $\begin{array}{l}\text { Upper confidence } \\
\text { interval }\end{array}$ & p-value \\
\hline $\begin{array}{l}\text { Model } 1 \\
\quad \text { Rehabilitation }\end{array}$ & 0.088 & 0.051 & 0.150 & $<0.001$ \\
\hline \multicolumn{5}{|l|}{ Model 2} \\
\hline Rehabilitation & 0.067 & 0.025 & 0.180 & $<0.001$ \\
\hline Age on study recruitment & 1.024 & 0.999 & 1.050 & 0.065 \\
\hline Diabetes mellitus & 1.603 & 1.039 & 2.474 & 0.033 \\
\hline Arterial hypertension & 1.272 & 0.562 & 2.879 & 0.564 \\
\hline PAOD & 1.415 & 0.881 & 2.275 & 0.151 \\
\hline $\mathrm{PCl}$ & 0.685 & 0.408 & 1.151 & 0.153 \\
\hline CABG & 1.472 & 0.847 & 2.559 & 0.170 \\
\hline Atrial fibrillation & 1.126 & 0.640 & 1.979 & 0.681 \\
\hline LVEF & 0.994 & 0.984 & 1.004 & 0.243 \\
\hline NSTEMI & 0.587 & 0.329 & 1.047 & 0.071 \\
\hline STEMI & 1.906 & 1.003 & 3.624 & 0.049 \\
\hline Other indications ${ }^{\star 2}$ & 1.282 & 0.488 & 2.930 & 0.946 \\
\hline Decompensated heart failure & 1.560 & 0.629 & 3.867 & 0.337 \\
\hline Single-vessel coronary artery disease & 1.204 & 0.435 & 3.330 & 0.721 \\
\hline Double-vessel coronary artery disease & 1.333 & 0.456 & 3.902 & 0.600 \\
\hline Triple-vessel coronary artery disease & 1.259 & 0.430 & 3.688 & 0.674 \\
\hline Creatinine & 1.004 & 1.002 & 1.005 & $<0.001$ \\
\hline HDL cholesterol & 0.750 & 0.405 & 1.390 & 0.361 \\
\hline WBC & 1.009 & 0.982 & 1.036 & 0.531 \\
\hline CRP & 0.997 & 0.990 & 1.004 & 0.348 \\
\hline Hemoglobin & 0.700 & 0.584 & 0.840 & $<0.001$ \\
\hline Angiotensin receptor blockers & 1.492 & 0.914 & 2.435 & 0.110 \\
\hline Diuretics & 1.826 & 0.977 & 3.413 & 0.059 \\
\hline Oral anticoagulants & 0.771 & 0.433 & 1.371 & 0.375 \\
\hline ASS & 0.635 & 0.319 & 1.264 & 0.196 \\
\hline P2 $Y_{12}$ inhibitors & 1.412 & 0.675 & 2.956 & 0.359 \\
\hline ASS $+P_{2} Y_{12}$ inhibitor & 1.226 & 0.554 & 2.713 & 0.615 \\
\hline Digitalis & 1.916 & 1.103 & 3.326 & 0.021 \\
\hline
\end{tabular}

${ }^{* 1}$ Model 1: univariate. Model 2 concerns prognostically relevant clinical parameters that differed between groups. Model 2 was therefore expanded to include the following variables: age on study recruitment, diabetes mellitus, arterial hypertension, PAOD, PCI, CABG, atrial fibrillation, LVEF, indication for inpatient admission, number of diseased vessels, creatinine, $\mathrm{HDL}$ cholesterol, WBC, CRP, hemoglobin, angiotensin receptor blockers, diuretics, oral anticoagulants, platelet aggregation inhibitors, and digitalis. ${ }^{* 2}$ Other indications: hypertensive emergency, tachycardic atrial fibrillation or other cardiac arrhythmia, pacemaker or ICD implantation, etc.

PAOD: Peripheral arterial occlusive disease; PCI: Percutaneous coronary intervention; CABG: Coronary artery bypass graft surgery; LVEF: Left ventricular ejection fraction; WBC: White blood cells; CRP: C-reactive protein; NSTEMI: Non-ST-elevation myocardial infarction; STEMl: ST-elevation myocardial infarction; HDL C: High-density lipoprotein cholesterol; ASS: Acetylsalicylic acid

nonparticipants who received digitalis glycoside was higher, at $14.5 \%$, than that of participants, at $5.8 \%$ $(\mathrm{p}<0.001)$. Those who did not undergo rehabilitation were more likely to suffer atrial fibrillation, which is potentially associated with this drug, than those who did $(44.3 \%$ versus $33.5 \%$; $=0.014)$ (Table 1$)$.

\section{Survival analyses}

Of the 315 patients who died during the observation period, $223(70.8 \%)$ died of heart disease; the remaining $92(29.2 \%)$ died from other causes. Figure 1 shows the Kaplan-Meier analysis for total mortality, comparing patients who did and did not undergo rehabilitation.
Of those who did, $0.2 \%$ died from non-cardiac causes and $2.3 \%$ from cardiac causes during follow-up, while of those who did not $7.3 \%$ died from non-cardiac causes and $16.9 \%$ from cardiac causes $(p<0.001$ in the log-rank test).

Initially, univariate Cox regression analysis was used to verify the effect of rehabilitation on the primary endpoint. Because there were substantial differences between the two groups for some variables (Table 1), multivariate Cox regression analysis was used to adjust the potential influencing factors (Table 2). The second model concerned prognostically relevant clinical parameters that differed between the two groups 


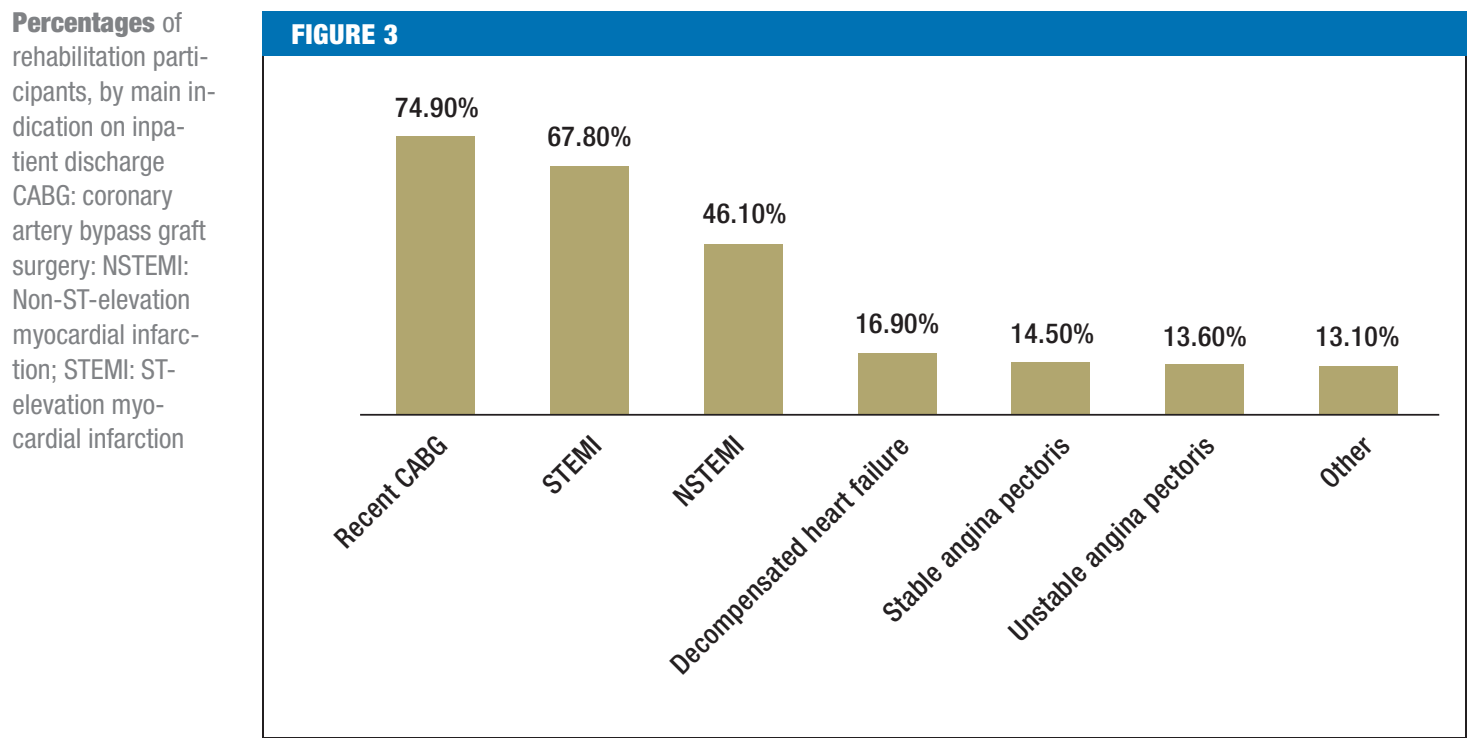

(Table 1). It was therefore expanded to include the following variables:

- Age on study recruitment

- Diabetes mellitus

- Arterial hypertension

- Peripheral arterial occlusive disease (PAOD)

- Percutaneous coronary intervention (PCI)

- Coronary artery bypass graft surgery (CABG)

- Atrial fibrillation

- Left ventricular ejection fraction (LVEF)

- Indication of inpatient admission

- I umber of affected vessels

- Creatinine level

- HDL cholesterol level

- WBC count

- CRP level

- Hemoglobin level

- Administration of angiotensin receptor blockers

- Administration of diuretics

- Oral anticoagulants

- Administration of platelet aggregation inhibitors

- Administration of digitalis (Table 2)

In the univariate Cox regression analysis (model 1) the finding of the Kaplan-Meier analysis is reflected in a survival advantage for patients who underwent cardiac rehabilitation over those who did not (hazard ratio [HR]: $0.088 ; 95 \%$ confidence interval $[95 \% \mathrm{CI}$ ]: 0.051 to $0.150 ; \mathrm{p}<0.001$ ). In model 2 , participation in rehabilitation was also associated with a substantial reduction in the primary endpoint, death, versus nonparticipation in rehabilitation, even accounting for potential influencing factors ( $\mathrm{HR}=0.067 ; 95 \% \mathrm{CI}$ : 0.025 to $0.180 ; \mathrm{p}<0.001$ ) (Table 2).

A particular group consisted of the 30 patients for whom rehabilitation was approved but who did not undergo it. In terms of baseline parameters this group was essentially identical to the total population $(72.4 \%$ male; age $68.2 \pm 10.2$ years; body mass index [BMI]: $27.5 \pm 5.9 \mathrm{~kg} / \mathrm{m}^{2}$, mainly patients with stable angina pectoris [37.9\%; ], etc.). However, this group's mortality was higher, at $37.9 \%$, during follow-up lasting a total of $116.3 \pm 75.9$ weeks.

\section{Discussion}

Book IX of the German Social Security Code governs the "rehabilitation and participation of disabled persons" and defines cases (following a heart attack or heart surgery, for decompensated heart failure, and others) in which outpatient or inpatient rehabilitation is indicated (11). These indications are based on knowledge obtained from both German and international studies, to the effect that participation in outpatient or inpatient rehabilitation improves the quality of life and prognosis of patients with serious heart disease $(7,8$, 12).

\section{Comparative studies conducted in Germany}

In three German studies on rehabilitation in patients with heart disease, the percentage of patients who participated in rehabilitation was higher than in the analyses presented here. In the OMEGA study, which involved 3851 patients all over Germany following myocardial infarction (I STEMI and STEMI with subsequent PCI), $70.6 \%$ of patients participated in cardiac rehabilitation. A benefit was demonstrated for rehabilitation in terms of total mortality, survived myocardial infarction, and onset of heart failure (13, 14). The percentage of patients who participated in rehabilitation following I STEMI (Figure 3) and following STEMI was also higher than in the data from 
Saxony-Anhalt described here (59\% versus $46.1 \%$ and $78 \%$ versus $67.8 \%$ respectively).

In the ACOS (Acute Coronary Syndrome) Registry, which also covers the whole of Germany, $60.1 \%$ of patients participated in rehabilitation following I STEMI or STEMI; $18 \%$ of recruiting hospitals were in the former East Germany. Here too, a reduction in the rate of major adverse cardiovascular events (MACEs) and mortality over a one-year period was recorded. The percentage of patients who underwent rehabilitation following STEMI was identical to that of this study (67.8\%), but the equivalent figure following I STEMI was higher: $52.3 \%$ versus $46.1 \%$ (Figure 3) (15).

Finally, we turn to the work of Schwaab et al. In their prospective registry study, which involved 1464 CHD patients from northwest Germany, $51.9 \%$ participated in rehabilitation (versus $28.9 \%$ in the analysis presented here). Unlike the OMEGA and ACOS studies, this study also included patients with unstable angina pectoris $(\mathrm{n}=352)$ and stable angina pectoris $(n=252)$. Here too, those who underwent rehabilitation benefited in terms of the onset of cardiovascular events when compared to those who did not undergo rehabilitation (16).

Comparing the figures for the whole of Germany to those of this study conducted in Saxony-Anhalt, and observing the improvement in prognosis of patients with CHD as a result of rehabilitation, it can be suspected that the low rehabilitation participation rate in Saxony-Anhalt revealed in this analysis contributes to the higher cardiac mortality rate in Saxony-Anhalt compared with other German states.

\section{Limitations}

However, as a limitation of study comparison it must be observed that while the OMEGA study, the ACOS study, and the study by Schwaab et al. involved patients who were at increased risk and underwent rehabilitation (14-16), in this study conducted in SaxonyAnhalt factors such as high age, diabetes mellitus, or arterial hypertension and reduced left ventricular function (Table 1) were more common among those who did not undergo rehabilitation. In addition, study design differs: our primary endpoint, total mortality, is different from that of the earlier studies (14-16).

Further limitations are the design of this analysis - which is a secondary evaluation of two studies that had other primary intentions - as well as the solely univariate subgroup analyses (some of which involved small case numbers) (eBox, eFigure), and the non-inclusion of psychosocial variables and aspects such as motivation for treatment and compliance, which are crucial both to successful rehabilitation and to a patient's decision to begin rehabilitation.

In addition, multivariate analysis does not ensure that differences between the two groups that existed before rehabilitation are accounted for or that the effect found can be explained solely by rehabilitation. This concerns in particular the group of patients for whom there was no formal indication for rehabilitation.

\section{Conclusion}

The information gathered on CHD patients following an acute inpatient hospital stay reveals the following:

- Participation in rehabilitation was lower than in other comparable studies.

- Participation in rehabilitation was associated with improved prognosis for patients.

- In the univariate subgroup analysis of this correlation it also existed for patients for whom there was no clear indication for rehabilitation according to Book IX of the German Social Security Code, such as patients with stable angina pectoris.

The data recorded here cannot clarify why only a small number of patients for whom rehabilitation is indicated according to Book IX of the German Social Security Code following I STEMI or decompensated heart failure began rehabilitation. However, notably, 175 of 727 patients for whom rehabilitation was approved did not participate in rehabilitation. It is likely that the main reason for this was patients' own decisions not to participate.

\section{KEY MESSAGES}

- Only $28.9 \%(n=552)$ of the investigated heart disease patients underwent rehabilitation following their inpatient hospital stay, although for at least 39\% $(n=727)$ of patients there was a clear indication for rehabilitation such as ST-elevation myocardial infarction (NSTEMI), non-ST-elevation myocardial infarction (STEMI), decompensated heart failure, or heart surgery.

- Regardless of main indication on discharge, total mortality among those who underwent rehabilitation was lower than among those who did not (hazard ratio: $0.067 ; 95 \%$ confidence interval: 0.025 to 0.180 ; $\mathrm{p}<0.001)$.

- Those who did not undergo rehabilitation were more likely to develop diabetes mellitus, arterial hypertension, or peripheral arterial occlusive disease and had lower left ventricular ejection fractions than those who did undergo rehabilitation.

- If one assumes that the low rehabilitation participation rate observed here can be extrapolated to the entire federal state of Saxony-Anhalt, and that rehabilitation participation rates are higher in other states, this may explain why cardiac mortality in Saxony-Anhalt is higher than in Germany as a whole.

\section{Conflict of interest statement}

Prof. Schlitt has received consultancy fees (Advisory Board) from Boehringe Ingelheim. He has received lecture fees and reimbursement of conference fees and travel expenses from Sanofi-Aventis, BMS, Pfizer, Novartis, Servier Boehringer Ingelheim, MSD, and Bayer AG. He has received study funding (third-party funds) from GSK, Sanofi-Aventis, Mitsubishi, Endotis, Bayer AG, Boehringer Ingelheim, Novartis, Actelion, and BMS.

The other authors declare that no conflict of interest exists. 
Manuscript received on 22 January 2015, revised version accepted on 5 May 2015.

Translated from the original German by Caroline Shimakawa-Devitt, M.A.

\section{REFERENCES}

1. Deutsche Herzstiftung (ed.): Deutscher Herzbericht 2013. $1^{\text {th }}$ edition. Frankfurt a. M.: Deutsche Herzstiftung 2013.

2. Nichols M, Townsend N, Luengo-Fernandez R, et al.: European cardiovascular disease statistics 2012. Brussels: European Heart Network and European Society of Cardiology 2012.

3. Heidemann C, Du Y, Schubert I, Rathmann W, Scheidt-Nave C: Prävalenz und zeitliche Entwicklung des bekannten Diabetes mellitus Ergebnisse der Studie zur Gesundheit Erwachsener in Deutschland (DEGS1). Bundesgesundheitsbl 2013; 56: 668-77.

4. Stang A, Stang M: An inter-state comparison of cardiovascular risk factors in Germany: towards an explanation of high ischemic heart disease mortality in Saxony-Anhalt. Dtsch Arztebl Int 2014; 111 : 530-6.

5. Kim C, Youn JE, Choi HE: The effect of a self-exercise program in cardiac rehabilitation for patients with coronary artery disease. Ann Rehabil Med 2011; 35: 381-7.

6. Kwan G, Balady GJ: Cardiac rehabilitation 2012: advancing the field through emerging science. Circulation 2012; 125: e369-73.

7. Gielen S, Laughlin MH, O'Conner C, Duncker DJ: Exercise training in patients with heart disease: review of beneficial effects and clinical recommendations. Prog Cardiovasc Dis 2015; 57: 347-55.

8. Anderson L, Taylor RS: Cardiac rehabilitation for people with heart disease: an overview of Cochrane systematic reviews. Cochrane Database Syst Rev 2014; 12: CD011273.

9. Hoepfner F, Jacob M, Ulrich C, et al.: Subgroups of monocytes predict cardiovascular events in patients with coronary heart disease, the PHAMOS-trial (Prospective Halle Monocytes Study). Clin Res Cardiol 2012; 101: Suppl 1.

10. Schulz S, Schlitt A, Lutze A, et al.: The importance of genetic variants in TNF $\alpha$ for periodontal disease in a cohort of coronary patients. J Clin Periodontol 2012; 39: 699-706.
11. Deutsche Leitlinie zur Rehabilitation von Patienten mit Herz-Kreislauferkrankungen (DLL-KardReha). Clin Res Cardiol 2007; Suppl 2: III/1-III/54.

12. Melamed RJ, Tillmann A, Kufleitner HE, Thürmer U, Dürsch M: Evaluating the efficacy of an education and treatment program for patients with coronary heart disease: A randomized controlled trial. Dtsch Arztebl Int 2014; 111: 802-8.

13. Maisch B: Kardiologische Rehabilitation - mehr als nur für den Schrebergarten? Herz 2012; 37: 7-11.

14. Rauch B, Riemer T, Schwaab B, et al. for the OMEGA study group: Short-term comprehensive cardiac rehabilitation after AMI is associated with reduced 1-year mortality: results from the OMEGA study. Eur J Prev Cardiol 2014; 21: 1060-9.

15. Jünger $C$, Rauch $B$, Schneider $S$, et al.: Effect of early short-term cardiac rehabilitation after acute ST-elevation and non-ST-elevation myocardial infarction on 1-year mortality. Curr Med Res Opin 2010; 26: 803-11.

16. Schwaab B, Waldmann A, Katalinic A, Sheikhzadeh A, Raspe H: In-patient cardiac rehabilitation versus medical care - a prospective multicentre controlled 12 months follow-up in patients with coronary heart disease. Eur J Cardiovasc Prev Rehabil 2011; 18: 581-6.

\section{Corresponding author:}

Prof. Dr. med. habil. Axel Schlitt, MHA

Paracelsus Heart Hospital Bad Suderode

Paracelsusstr. 1

06485 Quedlinburg, Germany

prof.dr.axel.schlitt@paracelsus-kliniken.de
Supplementary material eFigure, eBox: www.aerzteblatt-international.de/15m0527 


\section{Supplementary material to:}

\section{Rehabilitation in Patients With Coronary Heart Disease}

Participation and Its Effect on Prognosis

by Axel Schlitt, Patricia Wischmann, Andreas Wienke, Florian Hoepfner, Frank Noack, Rolf-Edgar Silber, and Karl Werdan

Dtsch Arztebl Int 2015; 112: 527-34. D0l: 10.3238/arztebl.2015.0527

\section{eBOX}

\section{Subgroup analysis}

Examining patient subgroups defined on the basis of main diagnosis on discharge, most were discharged with the diagnosis "stable angina pectoris" $(n=496)$. The other discharge diagnoses were divided between the main diagnoses "unstable angina pectoris" $(n=482)$, recent "coronary artery bypass graft surgery (CABG)" ( $n=291$, with and without heart valve replacement), "non-ST-elevation myocardial infarction (NSTEMI)" ( $n=206)$, "ST-elevation myocardial infarction (STEMI)" $(n=125)$, "decompensated heart failure" $(n=121)$, and other diagnoses $(n=189$ : hypertensive emergency, tachycardic atrial fibrillation or other cardiac arrhythmia, pacemaker or ICD implantation [ICD: implantable cardioverter defibrillator], etc.). In addition, subgroup analysis of participation in rehabilitation revealed a heterogeneous picture. For example, the percentage of rehabilitation participants who had been discharged from the Inpatient and Outpatient Center for Cardiothoracic Surgery was $74.9 \%$ following CABG, $67.8 \%$ following STEMI, but only $46.1 \%$ following NSTEMI and as low as $16.9 \%$ following an inpatient hospital stay for decompensated heart failure (Figure 3). However, in terms of total survival there is a benefit in favor of those who had undergone rehabilitation in every subgroup (eFigure). 

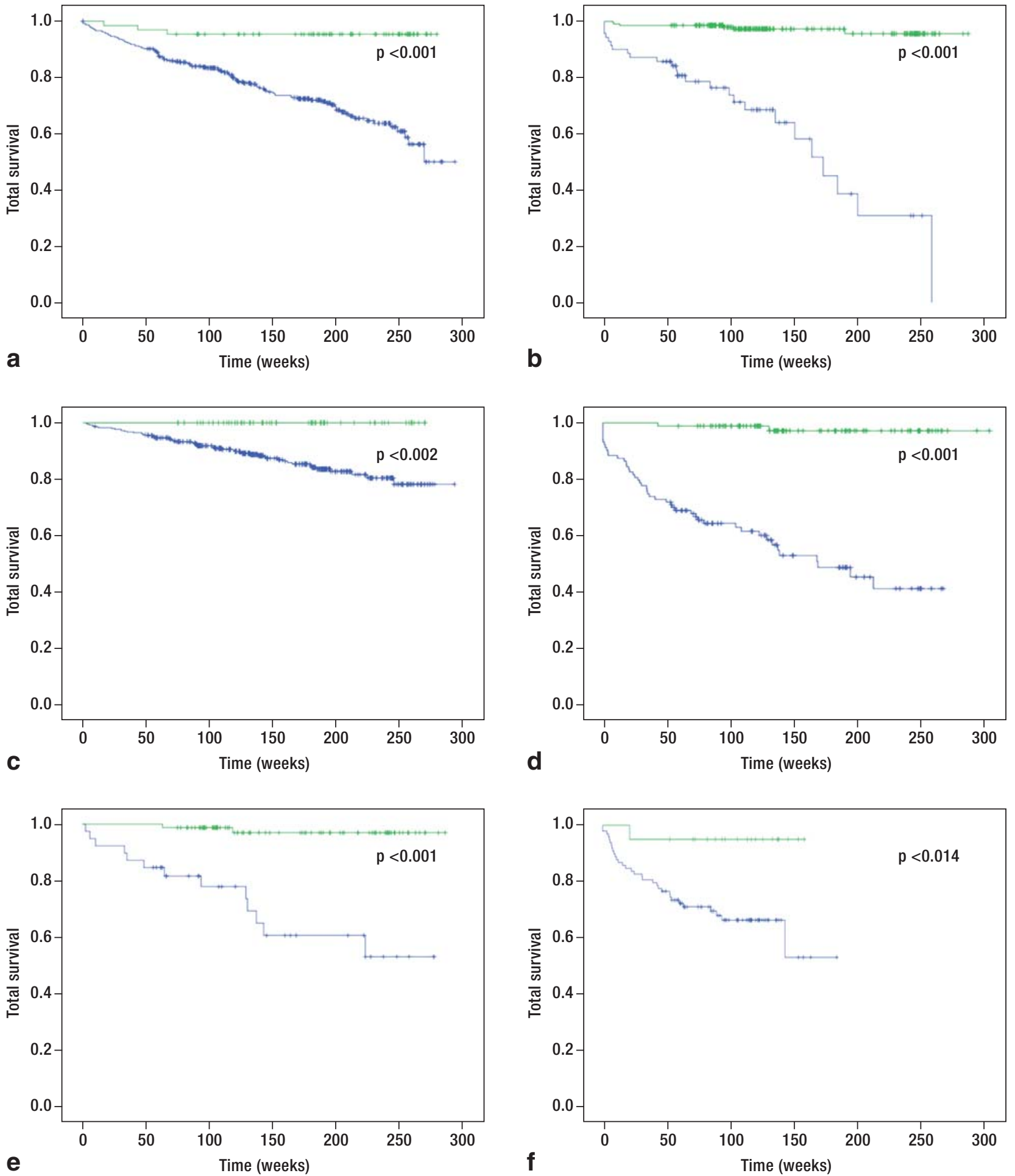

Kaplan-Meier analysis of total mortality, comparing those who underwent rehabilitation (green) versus those who did not (blue), by subgroups defined on the basis of main diagnosis on discharge: a) stable angina pectoris (66 patients who underwent rehabilitation versus 390 who did not), b) current condition following coronary artery bypass graft surgery (CABG) (209 patients who underwent rehabilitation versus 70 who did not), c) unstable angina pectoris (62 patients who underwent rehabilitation versus 394 who did not), d) non-ST-elevation myocardial infarction (NSTEMI) (88 patients who underwent rehabilitation versus 103 who did not), e) ST-elevation myocardial infarction (STEMI) (82 patients who underwent rehabilitation versus 39 who did not), f) decompensated heart failure (20 patients who underwent rehabilitation versus 98 who did not). The heterogeneous group of patients with various main diagnoses on discharge $(n=189)$ is not shown here. Statistical comparison performed using the log-rank test. 